\title{
Effect of Extrusion on the Hydrophilic Antioxidant Capacity of Four Whole Grains
}

\author{
Lingxiao Yang, Hui Zhang*, Lilin Cheng, Zhonghua Gu, Dan Hua, Xiguang Qi, Haifeng Qian, Li Wang \\ State Key Laboratory of Food Science and Technology \& School of Food Science and Technology, Jiangnan University, Wuxi, China \\ *Corresponding author: zhanghui@jiangnan.edu.cn
}

Received February 18, 2014; Revised March 06, 2014; Accepted March 10, 2014

\begin{abstract}
Cereal grains are generally subjected to thermal treatment before consumption. However, few data are available on total phenolic content (TPC), degree of starch gelatinization, phenolic acids, and antioxidant capacity of extruded whole grains based on trolox equivalent antioxidant capacity (TEAC), DPPH radical scavenging activity, and ferric reducing antioxidant potential (FRAP). Four whole grains, brown rice, wheat, maize, and barley were examined in this study. The free and bound TPCchanged significantly $(p<0.05)$ after extrusion. Morever, heat and degree of starch gelatinization could affect the bound TPC. In bound fraction, the antioxidant capacity was directly influenced by TPC. Extrusion $\left(110-140^{\circ} \mathrm{C}\right)$ can retain or improve the antioxidant capacity in its free and bound fractions. Phenolic acids are stable in their bound form. Results showed that the bound TPC and total phenolic acids have a strong relationship against antioxidant capacity, indicating that TPC is the major antioxidant in the bound fraction.
\end{abstract}

Keywords: whole grains, total phenolic content, antioxidant capacity, HPLC

Cite This Article: Lingxiao Yang, Hui Zhang, Lilin Cheng, Xiguang Qi, Haifeng Qian, and Li Wang, “Effect of Extrusion on the Hydrophilic Antioxidant Capacity of Four Whole Grains.” Journal of Food and Nutrition Research, vol. 2, no. 2 (2014): 80-87. doi: 10.12691/jfnr-2-2-4.

\section{Introduction}

Cereal grains are traditional Asian staple foods and a major source of daily energy intake. Nowadays, consumers prefer refined grains to whole grains because of the rough texture and unpleasant tastes of whole grains. However, most of the antioxidants are removed during the refining process $[1,2]$. Epidemiologic studies have shown that the intake of whole grain is associated with positive health benefits, such as lowered risks of chronic diseases like coronary heart diseases (CHD), type II diabetes, and cancer along with reduced mortality risk. This is attributed in part to the phytochemicals located in the edible parts of the whole grain, i.e. the bran, germ, and endosperm [3,4,5,6,7]. Phytochemicals, which include terpenoids, phenols, and alkaloids, are bioactive components of plants that provide many health benefits. It is believed that their antioxidant activities are key to the protection against some chronic diseases $[8,9]$. Therefore, encouraging people to consume more whole grains on a daily basis appears to be of great importance.

There has been much research into the antioxidant activity of whole grains. Most studies have focused on the use of various organic solvents to fully extract the antioxidants $[10,11]$. However, some studies have shown that such extraction methods underestimate the antioxidant capacity of whole grains because most of the antioxidants are in an insoluble bound form, i.e. they are bound to cell wall material [12,13]. Therefore, both free and bound phenolic contents should be considered.

Most of the literature describing the antioxidant capacity of whole grainsis focused on the raw materials $[11,12,14,15,16,17]$. Unlike vegetables and fruits, whole grains can hardly be eaten by humans without being cooked. Therefore, studies on the antioxidant capacity of unprocessed whole grains appear to be inadequate because different processes may have differing effects on the antioxidant content of whole grain. To the best of our knowledge, only a limited number of studies have reported the antioxidant content of processed whole grains $[18,19]$. Thus, it is necessary to investigate the antioxidant capacity of processed whole grains so that we can accurately evaluate their antioxidant activity.

The objective of this study was to investigate the effects of extrusion $\left(110-140^{\circ} \mathrm{C}\right)$ on phytochemical content (i.e. the total phenolic content (TPC), ferulic acid content and p-coumaric acid content), degree of starch gelatinizationand antioxidant capacity (i.e. DPPHradical scavenging capacity, trolox-equivalent antioxidant capacity [TEAC] and ferric reducing antioxidant potential [FRAP]) of four whole grains (i.e.maize, wheat, brown rice, and barley).

\section{Materials and methods}

\subsection{Materials}


Folin-Ciocalteu's reagent, 6-hydroxy-2,5,7,8tetramethylchroman-2-carboxylic acid (Trolox), 2,2'azino-bis(3-ethylbenzothiazoline-6-sulphonic acid) (ABTS), 2,2-diphenyl-1-picrylhydrazyl (DPPH), TakaDiastase from Aspergillus oryzae, ferulic acid, and $p$ coumaric acid were purchased from Sigma-Aldrich (St. Louis, MO). 2,4,6-Tri(2-pyridyl)-s-triazine (TPTZ) was purchased from Aladdin Technology Corporation (Shanghai, China). Methanol and acetonitrile of HPLC grade were purchased from J\&K Scientific Ltd (Beijing, China). Other chemicals used in this study were of analytical grade and purchased from Sinopharm Chemical Reagent Co., Ltd. (Shanghai, China).

Whole grain maize, wheat, brown rice and barley were purchased froma local supermarket in Wuxi, China. All whole grains were stored at $-20^{\circ} \mathrm{C}$ before use.

\subsection{Samples Preparation}

Whole grains were ground (Model FW100 grinder, Tianjin Taisite Instrument Co., Ltd., Tianjin, China) to produce a fine powder that would pass through a 60 mesh sieve. The grounds were stored at $-20^{\circ} \mathrm{C}$ before use. Extruded samples: Whole grain powder (1 kg) was obtained as described above, and the water content was adjusted to 25\%. Extrusion was carried out on a twinscrew extruder (Model POLYLAB, Thermo Fisher Scientific Inc., Massachusetts, USA) at a constant 100 $\mathrm{r} / \mathrm{min}$ screw speed and $60 \mathrm{~g} / \mathrm{min}$ mass flow rate. Four barrel temperature profiles were used: $70-80-90-110^{\circ} \mathrm{C}$, $70-80-100-120^{\circ} \mathrm{C}, \quad 70-80-100-130^{\circ} \mathrm{C}$, and $70-80-110-$ $140^{\circ} \mathrm{C}$.

All the samples obtained above were able to be consumed and then ground to produce a fine powder that would pass through a 60 mesh sieve. The grounds were stored at $-20^{\circ} \mathrm{C}$ before extraction.

\subsection{Determination of the Moisture Content}

For determination of the dry weight (DW), approximately $1 \mathrm{~g}$ of raw or processed sample was dried in a drying oven (Model DHG-9203A, Shanghai Yiheng Scientific Instrument Co., Ltd, Shanghai, China) at $105^{\circ} \mathrm{C}$ for $4 \mathrm{~h}$ until the sample reached a constant weight.

\subsection{Phenolic Extracts}

Extraction of free-soluble and insoluble-bound phenolic compounds was according to the method described by Sosulski [20] and modified in our lab. Free-soluble phenol: Whole grain flour samples $(10 \mathrm{~g})$ were extracted twice with $100 \mathrm{~mL}$ of $80 \%$ (v/v) aqueous ethanol for 10 min at ambient temperature and centrifuged at $4000 \mathrm{r} / \mathrm{min}$ for $10 \mathrm{~min}$ at $20^{\circ} \mathrm{C}$. The supernatants were collected, combined, and then evaporated under vacuum at $35^{\circ} \mathrm{C}$ in a rotary vacuum evaporator (Model RV10 basic, Guangzhou IKA Scientific Instrument Co., Ltd., Guangzhou, China) to dryness and reconstituted in 100 $\mathrm{mL}$ of water before two extractions with $n$-hexane to remove lipophilic contaminants. Insoluble-bound phenols: After the extraction of free-soluble phenols, the residue was digested with $100 \mathrm{~mL}$ of $2 \mathrm{M} \mathrm{NaOH}$ at ambient temperature for $1 \mathrm{~h}$, and an ultrasonic cleaning instrument (Model KQ2200DE, Kunshan Ultrasonic Instrument Co., Ltd., Kunshan,China) was used during the hydrolysis. The resultant hydrolysate was acidified to $\mathrm{pH}$ 6 with $\mathrm{HCl}$ and extracted three times with ethyl acetate. The ethyl acetate fraction was collected and evaporated to dryness under vacuum at $35^{\circ} \mathrm{C}$ and reconstituted in 100 $\mathrm{mL}$ of water, then extracted twice with $n$-hexane to remove lipophilic contaminants.

\subsection{Determination of TPC}

Briefly, $1 \mathrm{~mL}$ of the extract was thoroughly mixed with $1 \mathrm{~mL}$ of Folin-Ciocalteu reagent and $3 \mathrm{~mL}$ of $7.5 \%(\mathrm{w} / \mathrm{v})$ sodium carbonate solution [21]. The mixture was allowed to stand at ambient temperature for $2 \mathrm{~h}$. The absorbance was measured at $\lambda=765 \mathrm{~nm}$ with a Visible Spectrophotometer (Model 722S, Wuxi Keda Intelligent Instrument Co., Ltd., Wuxi, China). TPC was determined by means of a calibration curve prepared by using gallic acid and expressed as microgram gallic acid equivalent (GAE) per gram of whole grain (DW). Data are reported as mean \pm standard deviation (SD) for at least three replications.

\subsection{Determination of Starch Gelatinization Degree}

The degree of starch gelatinization of the extruded whole grains was determined according to Bhattacharya [22]. Briefly, 3 flasks of $100 \mathrm{~mL}$ were prepared which were marked as $A_{1}, A_{2}$ and $B$, respectively. 1 g of sample was placed in both $A_{1}$ and $A_{2}$ before $50 \mathrm{~mL}$ of water was added into the 3 flasks. In order to thoroughly gelatinize the starch, A1 was boiled in water for 20 min before it was cooled down to ambient temperature immediately. Then, $A_{1}, A_{2}, B$ were respectively added with $5 \mathrm{~mL}$ of $5 \%(\mathrm{w} / \mathrm{v})$ Taka-Diastase which were later water bathed in $38^{\circ} \mathrm{C}$ for 2 h. Enzymatic hydrolysis was paused by adding $2 \mathrm{~mL}$ of $1 \mathrm{M} \mathrm{HCl}$. The hydrolysates in $\mathrm{A}_{1}$ and $\mathrm{A}_{2}$ were obtained after centrifuging at $4000 \mathrm{r} / \mathrm{min}$ and water was added to the volume of $100 \mathrm{~mL}$. Mixing $10 \mathrm{~mL}$ of the hydrolysate with $10 \mathrm{~mL}$ of $0.01 \mathrm{M}$ iodine solution, $2 \mathrm{~mL}$ of $1 \mathrm{M}$ $\mathrm{H}_{2} \mathrm{SO}_{4}$ and $18 \mathrm{~mL}$ of $0.1 \mathrm{M} \mathrm{NaOH}$, then the mixture was titrated by $0.01 \mathrm{M} \mathrm{Na}_{2} \mathrm{~S}_{2} \mathrm{O}_{3} . \mathrm{V}_{1}, \mathrm{~V}_{2}, \mathrm{~V}_{0}$ represents the volume titrated for $A_{1}, A_{2}, B$, respectively. Starch gelatinization degree was calculated by the following formula: $\operatorname{SGD}(\%)=\left[\left(\mathrm{V}_{0}-\mathrm{V}_{1}\right) /\left(\mathrm{V}_{0}-\mathrm{V}_{2}\right)\right] \times 100$

\subsection{Scavenging Effects on DPPH Radical.}

Briefly, $0.1 \mathrm{~mL}$ of the extracted solution was mixed with a methanolic DPPH solution for which the absorbance at $\lambda=515 \mathrm{~nm}$ was diluted by methanol to 0.60 \pm 0.02 [23]. The absorbance of the mixture was measured at the end of the $30 \mathrm{~min}$ of incubation. The scavenging effect was calculated according to the following equation:

DPPH radical scavenging rate $(\%)=\left[\left(\mathrm{A}_{515}\right.\right.$ control $\mathrm{A}_{515}$ sample) $/ \mathrm{A}_{515}$ control] $\times 100$, where $\mathrm{A}$ control $=$ absorbance of DPPH radical + methanol, A sample = absorbance of DPPH radical + whole grain extract, and methanol was regarded as blank.

DPPH radical scavenging ability was expressed as the scavenging rate (\%) per gram of whole grain (DW). Data are reported as mean \pm SD for at least three replications.

\subsection{Determination of TEAC}


ABTS was prepared according to Re [24]. The ABTS was then diluted with water to produce a working solution with an absorbance of $0.70 \pm 0.02$ at $734 \mathrm{~nm}$. Each sample $(0.1 \mathrm{~mL})$ was mixed with $3.9 \mathrm{~mL}$ of working solution, and the decoloration was measured at $734 \mathrm{~nm}$ after $10 \mathrm{~min}$. TEAC was determined by means of a proper calibration curve created by using trolox at different concentrations. Data are reported as mean \pm SD for at least three replications.

\subsection{Determination of FRAP}

Briefly, $0.1 \mathrm{~mL}$ of each sample was mixed thoroughly with $3.0 \mathrm{~mL}$ of FRAP reagent before the mixture was incubated for $30 \mathrm{~min}$ at $37^{\circ} \mathrm{C}$ in a water bath[25]. The absorbance was measured at $\lambda=593 \mathrm{~nm}$. Different concentrations of $\mathrm{FeSO}_{4}$ were used to create the calibration curve. FRAP values were obtained from the calibration curve according to the absorbance of each sample and expressed as $\mathrm{mM} \mathrm{FeSO}_{4}$ equivalent per gram of whole grain (DW).

\subsection{Determination of Phenolic Acids by HPLC}

Ferulic and $p$-coumaric acid contents in free and bound phenolic fractions were determined by HPLC [15]. Briefly, $10 \mu \mathrm{L}$ of the extract was analyzed by HPLC (1260 Infinity, Agilent Technologies Co., Ltd., Santa Clara, USA) equipped with aG1311C quaternary pump, a G1316A column compartment, and a G1315D diode array detector. Separations were performed on a Waters LC-18 column $(4.6 \times 250 \mathrm{~mm}, 5 \mu \mathrm{m})$, with the column flow rate set to
$0.5 \mathrm{~mL} \mathrm{~min}^{-1}$ and the column temperature set to $25^{\circ} \mathrm{C}$. The mobile phase consisted of formic acid/water (1:99; v/v) (eluent A) and methanol/acetonitrile/formic acid (94:5:1; v/v/v) (eluent B). Gradient elution was used as follows: 0 min, 20\% B; $10 \mathrm{~min}, 30 \% \mathrm{~B} ; 15 \mathrm{~min}, 40 \% \mathrm{~B} ; 18 \mathrm{~min}$, $45 \% \mathrm{~B}$; $20 \mathrm{~min}, 50 \% \mathrm{~B}$; $30 \mathrm{~min}, 70 \% \mathrm{~B}$; and $40 \mathrm{~min}, 85 \%$ B. Ferulic and $p$-coumaric acid were identified by comparing the relative retention times of eluted compounds with those of pure standards at $\lambda=320 \mathrm{~nm}$. Ferulic and $p$-coumaric acids were quantified by an external standard method.

\subsection{Statistical Analysis.}

Values are shown as mean \pm SD $(n=3)$. Analysis of variance (one-way ANOVA) was used to test differences in values between treatments, with a significance level of $\alpha=0.05$. Relationship between the variables were determined by Pearson's regression analysis. All statistical analysis were performed with SPSS software (version 19).

\section{Results and Discussion}

\subsection{TPC of Raw and Extruded Grains}

The TPC of free and bound fractions (free and bound phenolic extracts)of raw and extruded whole grains ranged from $210.5 \pm 14.1$ to $670.0 \pm 16.4 \mu \mathrm{g}$ GAE $/ \mathrm{g} \mathrm{DW}$ and from $260.8 \pm 13.9$ to $1550.5 \pm 42.8 \mu \mathrm{g}$ GAE/g DW, respectively (Figure 1 ). There were significant differences between the raw and extruded whole grains for both free and bound fractions.
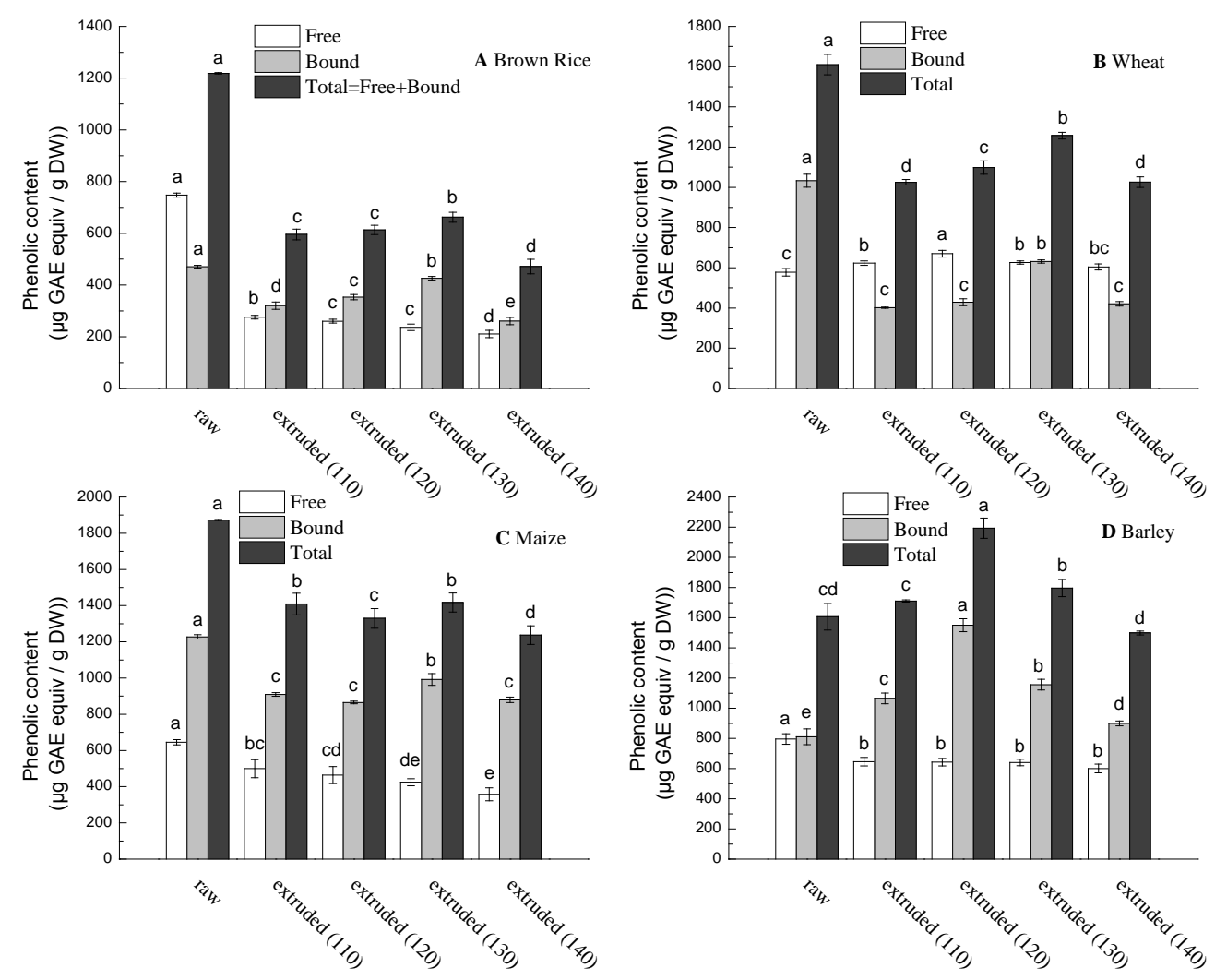

Figure 1. TPC of raw and extruded whole grains in free, bound and total fractions. Differences in values among free, bound and total fractions marked with different letters are significant $(\mathrm{p}<0.05)$. The letter $a$ represents the highest value 
With respect to free fractions, the TPC of brown rice (Figure $1 \mathrm{~A}$ ) was $747.7 \pm 8.0 \mu \mathrm{g} \mathrm{GAE} / \mathrm{g} \mathrm{DW}$ and significantly decreased $(\mathrm{p}<0.05$ ) by $63 \%, 65 \%, 68 \%$, and $72 \%$ after extrusion $\left(110-140^{\circ} \mathrm{C}\right)$, respectively. Similar trends were observed for maize and barley (Figure $1 \mathrm{~B}, \mathrm{D}$ ). However, the TPC of both maize and barley decreased less than that of brown rice under the same condition, indicating the TPC of brown rice is more susceptible than the others during extrusion. It is easy to comprehend that the TPC decreased as the temperature increased because more TPC can be decomposed at a higher temperature. Moreover, Chandrasekara [26] inferred that during thermal treatment, complexes can form between phenolics and macromolecules, making the phenolics less extractable. Interestingly, the TPC of wheat (Figure $1 \mathrm{~B}$ ) significantly increased by $8 \%, 16 \%$ and $8 \%$ after extrusion $\left(110-130^{\circ} \mathrm{C}\right)$, respectively. The increase in the free phenolic content of wheat indicates that extrusion may also have a postive effect on wheat. Dewanto [27] reported a significant increase of free TPC in sweet corn during hydrothermal treatment and attributed the increase to the liberation of the phenolic compounds from their bound forms [18].

With respect to bound fractions, the TPC of brown rice (Figure $1 \mathrm{~A}$ ) was $470.9 \pm 5.4 \mu \mathrm{g}$ GAE/g DW which significantly decreased by 32\%, 25\%, 10\%, and $45 \%$ after extrusion $\left(110-140^{\circ} \mathrm{C}\right)$, respectively $(\mathrm{p}<0.05)$. As for wheat and maize, similar trends were also observed (Figure $1 \mathrm{~B}, \mathrm{C})$. Interestingly, TPC of barley (Figure $1 \mathrm{D}$ ) increased by $31 \%, 91 \%, 43 \%$, and $11 \%$ after extrusion $\left(110-140^{\circ} \mathrm{C}\right)$, respectively $(\mathrm{p}<0.05)$. As is described above, phenolic compounds could be released from their bound forms after processing because of the heat. That probably is the reason why there will be a negative effect of extrusion on the bound TPC of the whole grains. It is noteworthy that a positive effect of extrusion on the bound TPC was also observed in barley. However, such a phenomenon had never been reported in previous studies $[18,19,27,28]$. It might be explained that extrusion may help the whole grains to be digested more thoroughly than the raw ones, which may have made the bound TPC easier to liberate and release more bound TPC during hydrolization. After determining the degree of starch gelatinization (Table 1), we found that the degree of starch gelatinization increased as the temperature increased. However, no significant enhancements were found of the values after the temperature increased to the certain point. As for brown rice, wheat and maize, the temperature is $130^{\circ} \mathrm{C}$. But for barley, the temperature is $120^{\circ} \mathrm{C}$. Therefore, the enhancement of degree of starch gelatinization may have some effects on improving the bound TPC. Previous studies reported that the digestibility of nutrients and phytochemicals in cereal grains could be improved during processing due to the gelatinization of starch [28,29] Compared with the other extrusion temperature, there was an apparent increase after extrusion at $130^{\circ} \mathrm{C}$ for brown rice, wheat and maize, and for barley at $120^{\circ} \mathrm{C}$. As for brown rice, wheat and maize, the heat decreased the bound TPC at first. With the degree of starch gelatinization increased, enhancement of the bound TPC gradually compensated the loss of the bound TPC which is caused by heat. However, after the degree of starch gelatinization stopped increasing, the heat started to decrease the bound TPC again. As for barley, the degree of starch gelatinization increased the bound TPC at first because the degree of starch gelatinization reached to the maximum value at a lower temperature than the others. Similarly, the heat started to decrease the bound TPC again after the degree of starch gelatinization stopped changing.

With respect to total fractions, the change of TPC was also significant $(\mathrm{p}<0.05)$ after extrusion $\left(110-140^{\circ} \mathrm{C}\right)$. The total TPC of brown rice (Figure 1 A) was $1218.6 \pm$ $2.6 \mu \mathrm{g} \mathrm{GAE} / \mathrm{g}$ DW which significantly decreased by $51 \%$, $50 \%$, 46\%, and $61 \%$ after extrusion $\left(110-140^{\circ} \mathrm{C}\right)$, respectively $(\mathrm{p}<0.05)$. The same trends were also observed for the other grains (Figure $1 \mathrm{~B}, \mathrm{C}$ ). As for the barley, however, it increased by $7 \%, 37 \%, 12 \%$ and $7 \%$. Correspondingly, these trends observed were similar as we observed on bound TPC indicating that the alteration occurred on total TPC is mainly decided by bound TPC, though total TPC is the combination of both free and bound TPC. This might be the reason of bound TPC's sufficiency in amount and stableness against heat. The certain temperatures on which the total TPC reenhancement took place explained that heat and the degree of starch gelatinization could still affect the total TPC.

Table 1. Degree of starch gelatinization of extruded whole grains under different temperatures

\begin{tabular}{|c|c|c|c|c|}
\hline \multirow[b]{2}{*}{ Temperature $/{ }^{\circ} \mathrm{C}$} & \multicolumn{4}{|c|}{ Degree of starch gelatinization ${ }^{\mathrm{a}}$ / \% } \\
\hline & 110 & 120 & 130 & 140 \\
\hline Brown rice & $84.2 \pm 0.8 c$ & $91.6 \pm 1.3 b$ & $97.1 \pm 0.8 \mathrm{a}$ & $98.0 \pm 1.1 \mathrm{a}$ \\
\hline Wheat & $85.1 \pm 0.9 c$ & $93.2 \pm 0.4 b$ & $96.7 \pm 0.5 a$ & $97.8 \pm 0.6 a$ \\
\hline Maize & $82.7 \pm 0.6 \mathrm{c}$ & $93.4 \pm 1.3 \mathrm{~b}$ & $97.4 \pm 0.7 \mathrm{a}$ & $97.9 \pm 0.6 \mathrm{a}$ \\
\hline Barley & $91.5 \pm 0.9 b$ & $96.8 \pm 1.6 \mathrm{a}$ & $98.1 \pm 0.6 \mathrm{a}$ & $98.4 \pm 0.8 \mathrm{a}$ \\
\hline
\end{tabular}

${ }^{\mathrm{a}}$ Values in the table are all expressed as mean \pm SD with 3 replications.The values in each row having the same letter are not significantly different (p $>$ 0.05). The letter $a$ represents the highest value in each row.

From the phenomenon above, it is reasonable to infer that the bound TPC of whole grains was spontaneously affected by heat which leads to the loss of bound TPC and degree of starch gelatinization which helps to increase the bound TPC. Perhaps the free phenols could permeate into the starch and wrapped by it during the process of starch gelatinization which leads to the protection of some free TPC from being decomposed by heat, and then be released during the extraction of bound phenols which in turn increases the bound TPC. Bound TPC, however, could hardly increase as the temperature keep climbing up due to the higher heat could still decompose the free phenols wrapped in the starch and release the phenols from their bound form into free form. Because of bound TPC's sufficiency and stableness, the alteration of total TPC was similar to that of bound TPC which means bound TPC plays a dominant role on the alteration of the total TPC during extrusion. Therefore, extrusion can significantly 
change TPC of whole grains both in free and bound fractions $(p<0.05)$. Both the heat and the degree of starch gelatinization could affect TPC of whole grains. Therefore, adopting an appropriate temperature to process whole grains can retain or improve the TPC to the highest extent.

\subsection{Antioxidant Capacity of Raw and Extruded Grains}

To properly evaluate the antioxidant capacity of raw and extruded whole grains, DPPH radical scavenging activity, TEAC and FRAP were used to determine the antioxidant capacity. DPPH and ABTS radicals are scavenged by antioxidants through the donation of hydrogen to form colourless compounds, and the reduction of their colour could be quantified at the wavelength of $515 \mathrm{~nm}$ and $734 \mathrm{~nm}$. FRAP assay is used to determine the ability of the antioxidant to reduce $\mathrm{Fe}^{3+}$ to $\mathrm{Fe}^{2+}$ with the presence of TPTZ at low $\mathrm{pH}$. Once $\mathrm{Fe}^{3+}$ is reduced to $\mathrm{Fe}^{2+}$, blue compound $\mathrm{Fe}^{2+}-\mathrm{TPTZ}$ could be formed and the colour could be quantified at the wavelength of $593 \mathrm{~nm}[16]$. In the present study, the TEAC and FRAP assay was performed in an aqueous system, thus only the hydrophilic antioxidant capacity was measured.
In the free fraction of brown rice, the antioxidant capacity changed significantly $(\mathrm{p}<0.05)$ after extrusion (Table 2). The results showed that over half of its initial TEAC and FRAP value were lost during extrusion (110$140^{\circ} \mathrm{C}$ ). A similar trend was also observed in the DPPH radical scavenging ability. As for wheat, extruded wheats exhibited stronger antioxidant capacity than the raw one. Its DPPH radical scavenging ability significantly increased $(p<0.05$ ) by 38\%, 259\%, 111\%, and 98\% after extrusion $\left(110-140^{\circ} \mathrm{C}\right)$, respectively. Similar results were also obtained with the TEAC value. However, FRAP value decreased slightly after processing except for extrusion $\left(120^{\circ} \mathrm{C}\right)$, which increased by $74 \%(\mathrm{p}<0.05)$. It is noteworthy that a remarkable increase in TEAC value, DPPH radical scavenging ability, and FRAP value was obtained after extrusion at $120^{\circ} \mathrm{C}$. As for maize, both TEAC and FRAP values did not significantly change ( $\mathrm{p}>$ $0.05)$ during extrusion $\left(110-130^{\circ} \mathrm{C}\right)$, whereas there is a slight decrease $(\mathrm{p}<0.05)$ after extrusion at $140^{\circ} \mathrm{C}$. In contrast, the FRAP value significantly decreased after extrusion $\left(110-140^{\circ} \mathrm{C}\right)$. As for barley, no significant increase $(p>0.05)$ was found after extrusion $\left(110-140^{\circ} \mathrm{C}\right)$ for TEAC value. A similar trend was also shown for FRAP value. However, DPPH radical scavenging ability significantly increased.

Table 2. TEAC, DPPH, and FRAP values in the free and bound fractions of unprocessed and processed grains

\begin{tabular}{|c|c|c|c|c|c|c|}
\hline \multirow[b]{2}{*}{ Samples } & \multicolumn{2}{|c|}{$\begin{array}{c}\text { TEAC }^{\mathrm{a}} \\
(\mu \mathrm{mol} \text { Trolox equiv/g DW) } \\
\end{array}$} & \multicolumn{2}{|c|}{$\begin{array}{c}\mathrm{DPPH}^{\mathrm{a}, \mathrm{b}} \\
\text { (Inhibition rate per gram DW) }\end{array}$} & \multicolumn{2}{|c|}{$\begin{array}{c}\text { FRAP }^{\mathrm{a}} \\
\left(\mu \mathrm{mol} \mathrm{FeSO} \mathrm{F}_{4} \text { equiv/g DW) }\right.\end{array}$} \\
\hline & Free & Bound & Free & Bound & Free & Bound \\
\hline & \multicolumn{6}{|c|}{ Brown rice } \\
\hline Raw & $4.52 \pm 0.05 \mathrm{a}$ & $4.97 \pm 0.13 a$ & $2.63 \pm 0.07 \mathrm{a}$ & $2.07 \pm 0.05 a$ & $9.86 \pm 0.31 \mathrm{a}$ & $7.03 \pm 0.26 \mathrm{a}$ \\
\hline Extruded $\left(110^{\circ} \mathrm{C}\right)$ & $1.15 \pm 0.14 \mathrm{c}$ & $3.53 \pm 0.10 \mathrm{~d}$ & $2.02 \pm 0.09 \mathrm{~b}$ & $1.62 \pm 0.06 \mathrm{~b}$ & $2.57 \pm 0.20 \mathrm{e}$ & $4.84 \pm 0.11 \mathrm{~d}$ \\
\hline Extruded $\left(120^{\circ} \mathrm{C}\right)$ & $1.77 \pm 0.20 \mathrm{~b}$ & $3.91 \pm 0.06 \mathrm{c}$ & $1.91 \pm 0.07 \mathrm{bc}$ & $1.73 \pm 0.08 \mathrm{~b}$ & $2.95 \pm 0.26$ de & $5.49 \pm 0.12 c$ \\
\hline Extruded $\left(130^{\circ} \mathrm{C}\right)$ & $1.83 \pm 0.10 \mathrm{~b}$ & $4.43 \pm 0.06 b$ & $1.81 \pm 0.13 \mathrm{c}$ & $1.99 \pm 0.13 \mathrm{a}$ & $3.46 \pm 0.11 b c$ & $6.41 \pm 0.24 b$ \\
\hline \multirow[t]{2}{*}{ Extruded $\left(140^{\circ} \mathrm{C}\right)$} & $1.87 \pm 0.25 b$ & $3.09 \pm 0.06 \mathrm{e}$ & $1.59 \pm 0.06 \mathrm{~d}$ & $1.42 \pm 0.08 \mathrm{c}$ & $3.18 \pm 0.12 \mathrm{~cd}$ & $4.53 \pm 0.11 \mathrm{~d}$ \\
\hline & \multicolumn{6}{|c|}{ Wheat } \\
\hline Raw & $3.02 \pm 0.13 \mathrm{c}$ & $9.92 \pm 0.34 \mathrm{a}$ & $1.08 \pm 0.08 \mathrm{~d}$ & $3.77 \pm 0.06 \mathrm{a}$ & $5.60 \pm 0.31 b$ & $17.38 \pm 0.80 \mathrm{a}$ \\
\hline Extruded $\left(110^{\circ} \mathrm{C}\right)$ & $3.77 \pm 0.20 \mathrm{bc}$ & $4.37 \pm 0.11 \mathrm{c}$ & $1.49 \pm 0.11 \mathrm{c}$ & $2.02 \pm 0.03 \mathrm{c}$ & $3.80 \pm 0.26 c$ & $6.56 \pm 0.36 \mathrm{c}$ \\
\hline Extruded $\left(120^{\circ} \mathrm{C}\right)$ & $5.82 \pm 0.67 \mathrm{a}$ & $4.43 \pm 0.08 c$ & $3.86 \pm 0.09 a$ & $2.04 \pm 0.03 c$ & $9.73 \pm 0.25 \mathrm{a}$ & $6.73 \pm 0.23 c$ \\
\hline Extruded $\left(130^{\circ} \mathrm{C}\right)$ & $4.22 \pm 0.35 b$ & $5.80 \pm 0.14 b$ & $2.28 \pm 0.05 b$ & $2.64 \pm 0.05 b$ & $5.72 \pm 0.21 b$ & $8.88 \pm 0.28 b$ \\
\hline \multirow[t]{2}{*}{ Extruded $\left(140^{\circ} \mathrm{C}\right)$} & $3.21 \pm 0.46 \mathrm{c}$ & $4.55 \pm 0.17 \mathrm{c}$ & $2.13 \pm 0.13 b$ & $2.03 \pm 0.04 \mathrm{c}$ & $5.18 \pm 0.24 b$ & $6.75 \pm 0.23 c$ \\
\hline & \multicolumn{6}{|c|}{ Maize } \\
\hline Raw & $3.94 \pm 0.27 \mathrm{ab}$ & $11.55 \pm 0.29 \mathrm{a}$ & $2.52 \pm 0.08 \mathrm{ab}$ & $4.44 \pm 0.09 a$ & $8.40 \pm 0.72 \mathrm{a}$ & $19.88 \pm 0.38 a$ \\
\hline Extruded $\left(110^{\circ} \mathrm{C}\right)$ & $3.89 \pm 0.23 a b$ & $9.51 \pm 0.14 \mathrm{c}$ & $2.74 \pm 0.16 \mathrm{a}$ & $3.88 \pm 0.13 b$ & $6.74 \pm 0.36 b$ & $14.54 \pm 0.43 c$ \\
\hline Extruded $\left(120^{\circ} \mathrm{C}\right)$ & $4.20 \pm 0.28 \mathrm{a}$ & $9.17 \pm 0.06 \mathrm{c}$ & $2.56 \pm 0.14 \mathrm{ab}$ & $3.73 \pm 0.05 b$ & $6.18 \pm 0.26 b$ & $14.11 \pm 0.60 \mathrm{c}$ \\
\hline Extruded $\left(130^{\circ} \mathrm{C}\right)$ & $4.22 \pm 0.22 \mathrm{a}$ & $10.49 \pm 0.14 b$ & $2.42 \pm 0.11 b$ & $4.18 \pm 0.18 \mathrm{a}$ & $5.55 \pm 0.31 \mathrm{c}$ & $16.19 \pm 0.72 b$ \\
\hline \multirow[t]{2}{*}{ Extruded $\left(140^{\circ} \mathrm{C}\right)$} & $3.43 \pm 0.22 \mathrm{~b}$ & $9.36 \pm 0.10 \mathrm{c}$ & $2.16 \pm 0.13 \mathrm{c}$ & $3.84 \pm 0.13 b$ & $4.35 \pm 0.46 \mathrm{~d}$ & $14.44 \pm 0.40 \mathrm{c}$ \\
\hline & \multicolumn{6}{|c|}{ Barley } \\
\hline Raw & $5.56 \pm 0.17 \mathrm{a}$ & $7.41 \pm 0.28$ e & $3.14 \pm 0.10 b$ & $3.01 \pm 0.15 \mathrm{~d}$ & $10.40 \pm 0.44 \mathrm{a}$ & $10.78 \pm 0.31 \mathrm{~d}$ \\
\hline Extruded $\left(110^{\circ} \mathrm{C}\right)$ & $6.09 \pm 0.63 \mathrm{a}$ & $10.39 \pm 0.21 \mathrm{c}$ & $3.87 \pm 0.12 \mathrm{a}$ & $4.83 \pm 0.18 b$ & $9.53 \pm 0.70 b$ & $15.67 \pm 0.62 b$ \\
\hline Extruded $\left(120^{\circ} \mathrm{C}\right)$ & $6.23 \pm 0.32 \mathrm{a}$ & $13.97 \pm 0.29 \mathrm{a}$ & $3.80 \pm 0.14 \mathrm{a}$ & $5.86 \pm 0.14 \mathrm{a}$ & $9.58 \pm 0.53 b$ & $21.79 \pm 1.40 \mathrm{a}$ \\
\hline Extruded $\left(130^{\circ} \mathrm{C}\right)$ & $6.20 \pm 0.21 \mathrm{a}$ & $11.36 \pm 0.38 b$ & $3.73 \pm 0.26 \mathrm{a}$ & $4.87 \pm 0.12 b$ & $9.65 \pm 0.24 b$ & $16.77 \pm 0.71 b$ \\
\hline Extruded $\left(140^{\circ} \mathrm{C}\right)$ & $6.28 \pm 0.36 \mathrm{a}$ & $8.82 \pm 0.22 \mathrm{~d}$ & $3.74 \pm 0.21 \mathrm{a}$ & $4.13 \pm 0.12 c$ & $9.35 \pm 0.43 b$ & $13.38 \pm 0.44 \mathrm{c}$ \\
\hline
\end{tabular}

${ }^{\mathrm{a}}$ Values in the table are all expressed as mean \pm SD with 3 replications and referred to the dry weight. ${ }^{\mathrm{b}}$ The values obtained by the method described before were recalculated and referred to one gram of dried weight. The values in each column having the same letter are not significantly different (p > 0.05). The letter $a$ represents the highest value in each column.

In the bound fraction of 4 grains, we found a similar trend of the antioxidant capacity (TEAC, DPPH radical scavenging ability and FRAP) of brown rice with its bound TPC. Compared with the results shown in Figure 1 and Table 2, the antioxidant capacity of wheat, maize, and barley was also in line with their bound TPC after

processing. Correlation analysis (Table 4) showed a statistically high positive correlation between TPC and its antioxidant capacity (for TEAC: $\mathrm{r}=0.988, \mathrm{p}<0.01$; for DPPH: $r=0.978, p<0.01$; for FRAP: $r=0.979, \mathrm{p}<0.01$ ) The results could be explained by the fact that bound TPC is mainly responsible for the antioxidant capacity in its 
bound form. The change in bound TPC could directly reflect a variation in the antioxidant capacity of whole grains.

In addition, correlation analysis between total TPC and antioxidant capacity was tested. The results (Table 4) still showed a statistically high positive correlation between total TPC and its antioxidant capacity (for TEAC: $\mathrm{r}=$ 0.914, $\mathrm{p}<0.01$; for DPPH: $\mathrm{r}=0.768$, $\mathrm{p}<0.01$; for FRAP: $r=0.937, p<0.01)$. Though the correlation coefficient between total TPC and antioxidant capacity decreased a little for the cause of free TPC, high positive correlation between them still shows that TPC is the main antioxidant of whole grain.

To summarize, the antioxidant capacity of these four whole grains can be significantly affected by extrusion both in free and bound fractions. In the free fraction, the antioxidant capacity of extruded wheat can be well retained or improved during processing, which could be contributed by the enhancement of the free TPC in wheat because the free TPC are better extracted after extrusion along with some other antioxidants (e.g. amino acid). A previous study also found a remarkable enhancement of antioxidant capacity after processing[30]. However, brown rice lost a high proportion of its original antioxidant capacity after processing, compared with the other three grains, which may demonstrate that the antioxidants in brown rice are more vulnerable and thermally sensitive than the others. Although the FRAP,
TEAC, and DPPH assays used in this study were based on varied chemical principles, the values of DPPH radical scavenging activity were relatively higher than that of TEAC when compared with both of their original values. Because DPPH test was performed in the methanolic system instead of the aqueous system, which demonstrated that the antioxidant might exert higher antioxidant capacity in the methanolic system than aqueous system. Previous studies found lower antioxidant capacity in polar solvents because hydrogen bonding may cause dramatic changes in the $\mathrm{H}$-atom donor activities of phenolic antioxidants [31M32]. As for the bound fraction, the variation in the antioxidant capacity of the 4 grains is associated with the change in its bound TPC, which indicates that the antioxidant capacity is mainly ruled by its bound TPC. Information gathered by previous studies has suggested the bound TPC may survive upper gastrointestinal digestion conditions and reach the colon to exert its health benefits locally after absorption $[6,12]$.

\subsection{Content of Phenolic Acid of Raw and Extruded Grains}

As reported by previous studies [33,34], ferulic and $p$ coumaric acids are regarded as the major phenolic acids in whole grains. Table 3 shows the content of ferulic and $p$ coumaric acids in the free and the bound fractions for both processed and unprocessed whole grains.

Table 3. Content (micrograms per gram of dried weight) of ferulic acid and p-coumaric acid in free and insoluble bound phenolic extracts in different samples

\begin{tabular}{|c|c|c|c|c|c|c|}
\hline \multirow[b]{2}{*}{ Samples } & \multicolumn{3}{|c|}{$\begin{array}{c}\text { Free } \\
(\mu \mathrm{g} / \mathrm{g} D W)\end{array}$} & \multicolumn{3}{|c|}{$\begin{array}{c}\text { Bound } \\
(\mu \mathrm{g} / \mathrm{g} D W)\end{array}$} \\
\hline & Ferulic acid $^{\mathrm{a}}$ & $p$-coumaric acid ${ }^{\mathrm{a}}$ & Total $^{\mathrm{a}, \mathrm{b}}$ & Ferulic acid $^{\mathrm{a}}$ & $p$-coumaric acid ${ }^{\mathrm{a}}$ & Total $^{\mathrm{a}, \mathrm{b}}$ \\
\hline & \multicolumn{6}{|c|}{ Brown rice } \\
\hline Raw & $49.86 \pm 0.48 \mathrm{a}$ & $30.60 \pm 0.73 \mathrm{a}$ & $80.46 \pm 1.20 \mathrm{a}$ & $299.03 \pm 0.98 \mathrm{a}$ & $145.81 \pm 3.15 \mathrm{a}$ & $444.84 \pm 4.12 \mathrm{a}$ \\
\hline Extruded $\left(110^{\circ} \mathrm{C}\right)$ & $1.66 \pm 0.01 \mathrm{~d}$ & $2.26 \pm 0.04 \mathrm{~d}$ & $3.93 \pm 0.05 \mathrm{~d}$ & $177.14 \pm 2.23 \mathrm{~d}$ & $80.48 \pm 0.12$ e & $257.63 \pm 2.35 \mathrm{~d}$ \\
\hline Extruded $\left(120^{\circ} \mathrm{C}\right)$ & $9.29 \pm 0.24 b$ & $5.50 \pm 0.06 b$ & $14.79 \pm 0.30 \mathrm{~b}$ & $233.29 \pm 1.94 \mathrm{c}$ & $101.67 \pm 0.43 \mathrm{c}$ & $334.96 \pm 2.36 c$ \\
\hline Extruded $\left(130^{\circ} \mathrm{C}\right)$ & $5.00 \pm 0.07 c$ & $1.31 \pm 0.00 \mathrm{e}$ & $6.31 \pm 0.08 \mathrm{c}$ & $264.74 \pm 1.38 b$ & $129.67 \pm 0.31 b$ & $394.41 \pm 1.69 \mathrm{~b}$ \\
\hline \multirow[t]{2}{*}{ Extruded $\left(140^{\circ} \mathrm{C}\right)$} & $0.89 \pm 0.01 \mathrm{e}$ & $4.02 \pm 0.17 \mathrm{C}$ & $4.91 \pm 0.18 \mathrm{~d}$ & $163.33 \pm 1.10 \mathrm{e}$ & $85.61 \pm 0.37 \mathrm{~d}$ & $248.93 \pm 1.48 \mathrm{e}$ \\
\hline & \multicolumn{6}{|c|}{ Wheat } \\
\hline Raw & $19.47 \pm 0.24 \mathrm{~b}$ & $12.27 \pm 0.68 \mathrm{a}$ & $31.73 \pm 0.91 \mathrm{a}$ & $735.99 \pm 0.70 \mathrm{a}$ & $52.79 \pm 0.75 \mathrm{a}$ & $788.78 \pm 0.05 \mathrm{a}$ \\
\hline Extruded $\left(110^{\circ} \mathrm{C}\right)$ & $4.74 \pm 0.22 \mathrm{~d}$ & $2.07 \pm 0.02 \mathrm{c}$ & $6.81 \pm 0.24 \mathrm{~d}$ & $313.66 \pm 4.28 \mathrm{~d}$ & $40.31 \pm 0.45 c$ & $353.96 \pm 4.74 \mathrm{e}$ \\
\hline Extruded $\left(120^{\circ} \mathrm{C}\right)$ & $4.39 \pm 0.16 \mathrm{~d}$ & $3.48 \pm 0.02 b$ & $7.87 \pm 0.18 \mathrm{~cd}$ & $315.99 \pm 7.98 \mathrm{~d}$ & $45.25 \pm 1.91 \mathrm{~b}$ & $361.24 \pm 9.89$ de \\
\hline Extruded $\left(130^{\circ} \mathrm{C}\right)$ & $1.34 \pm 0.01 \mathrm{e}$ & $1.19 \pm 0.01 \mathrm{~d}$ & $2.53 \pm 0.02 \mathrm{e}$ & $320.54 \pm 3.57 \mathrm{~d}$ & $45.54 \pm 0.46 b$ & $366.08 \pm 4.03 \mathrm{~d}$ \\
\hline \multirow[t]{2}{*}{ Extruded $\left(140^{\circ} \mathrm{C}\right)$} & $0.99 \pm 0.01 \mathrm{e}$ & $0.91 \pm 0.01 \mathrm{~d}$ & $1.91 \pm 0.03 \mathrm{e}$ & $312.96 \pm 1.44 \mathrm{~d}$ & $41.72 \pm 0.18 \mathrm{c}$ & $354.68 \pm 1.62 \mathrm{e}$ \\
\hline & \multicolumn{6}{|c|}{ Maize } \\
\hline Raw & $37.70 \pm 0.64 \mathrm{a}$ & $23.82 \pm 0.90 \mathrm{a}$ & $61.53 \pm 1.54 \mathrm{a}$ & $1007.02 \pm 3.30 \mathrm{a}$ & $171.03 \pm 2.88 \mathrm{a}$ & $1178.05 \pm 6.18 \mathrm{a}$ \\
\hline Extruded $\left(110^{\circ} \mathrm{C}\right)$ & $12.11 \pm 0.35 b$ & $0.78 \pm 0.01 \mathrm{bc}$ & $12.89 \pm 0.37 b$ & $814.07 \pm 5.84 \mathrm{~d}$ & $134.45 \pm 0.70 \mathrm{~d}$ & $948.52 \pm 6.54 \mathrm{~d}$ \\
\hline Extruded $\left(120^{\circ} \mathrm{C}\right)$ & $2.85 \pm 0.17 \mathrm{c}$ & $1.59 \pm 0.01 \mathrm{~b}$ & $4.44 \pm 0.18 \mathrm{c}$ & $830.43 \pm 2.17 \mathrm{c}$ & $135.03 \pm 1.07 \mathrm{~d}$ & $965.45 \pm 3.24 \mathrm{c}$ \\
\hline Extruded $\left(130^{\circ} \mathrm{C}\right)$ & $1.62 \pm 0.02 \mathrm{~d}$ & $1.18 \pm 0.00 \mathrm{bc}$ & $2.80 \pm 0.03$ de & $906.67 \pm 3.37 b$ & $151.76 \pm 0.35 b$ & $1058.43 \pm 3.72 b$ \\
\hline \multirow[t]{2}{*}{ Extruded $\left(140^{\circ} \mathrm{C}\right)$} & $1.22 \pm 0.06 \mathrm{~d}$ & $0.65 \pm 0.01 \mathrm{c}$ & $1.86 \pm 0.07 \mathrm{e}$ & $767.28 \pm 1.81 \mathrm{e}$ & $145.54 \pm 1.15 \mathrm{c}$ & $912.82 \pm 2.96 \mathrm{e}$ \\
\hline & \multicolumn{6}{|c|}{ Barley } \\
\hline Raw & $26.81 \pm 0.41 \mathrm{a}$ & $16.15 \pm 0.14 \mathrm{a}$ & $42.96 \pm 0.27 \mathrm{a}$ & $418.24 \pm 4.89 \mathrm{~d}$ & $251.56 \pm 7.58 \mathrm{c}$ & $669.81 \pm 2.69 \mathrm{~d}$ \\
\hline Extruded $\left(110^{\circ} \mathrm{C}\right)$ & $3.29 \pm 0.08 \mathrm{~d}$ & $2.81 \pm 0.01 \mathrm{c}$ & $6.10 \pm 0.10 \mathrm{~d}$ & $500.46 \pm 4.49 \mathrm{c}$ & $252.11 \pm 0.48 \mathrm{c}$ & $752.56 \pm 4.97 \mathrm{c}$ \\
\hline Extruded $\left(120^{\circ} \mathrm{C}\right)$ & $5.01 \pm 0.12$ c & $2.48 \pm 0.01 \mathrm{~d}$ & $7.49 \pm 0.13 c$ & $795.40 \pm 4.33 \mathrm{a}$ & $368.94 \pm 1.11 \mathrm{a}$ & $1164.35 \pm 5.44 \mathrm{a}$ \\
\hline Extruded $\left(130^{\circ} \mathrm{C}\right)$ & $6.09 \pm 0.07 b$ & $5.29 \pm 0.06 b$ & $11.38 \pm 0.14 b$ & $620.54 \pm 2.74 b$ & $278.52 \pm 0.61 b$ & $899.05 \pm 3.35 b$ \\
\hline Extruded $\left(140^{\circ} \mathrm{C}\right)$ & $5.06 \pm 0.24 c$ & $2.89 \pm 0.00 \mathrm{c}$ & $7.94 \pm 0.24 \mathrm{c}$ & $385.73 \pm 3.46 \mathrm{e}$ & $182.05 \pm 0.09 \mathrm{~d}$ & $567.77 \pm 3.56 \mathrm{e}$ \\
\hline
\end{tabular}

${ }^{\mathrm{a}}$ Values in the table are all expressed as mean + SD with 3 replications and referred to the dry weight. ${ }^{\mathrm{b}}$ The total values were obtained by summing each single replicate of each compound. The values in each column having the same letter are not significantly different (p $>0.05$ ). The letter $a$ represents the highest value in each column.

In the free fraction of brown rice, the content of ferulic and $p$-coumaric acids was $49.9 \pm 0.5$ and $30.6 \pm 0.7 \mu \mathrm{g} / \mathrm{g}$ DW. About 95\%, 82\%, 92\%, and 94\% of its total phenolic acids were lost after extrusion $\left(110-140^{\circ} \mathrm{C}\right)$. The negative effect of extrusion on the total phenolic acids is very notable $(\mathrm{p}<0.05)$. A similar trend was also observed in wheat, maize, and barley. Over $70 \%$ of their total free phenolic acid were lost, which indicates some oxidation 
took place during extrusion. In contrast, other authors did not find any significant decrease in total phenolic acids contents after extrusion $\left(120-200^{\circ} \mathrm{C}\right)$ of buckwheat groat, perhaps due to different conditions and different grains [19]. A previous study has reported that phenolic acids could be released from their bound form into the free form to increase the phenolic content in the free fraction [27]. However, no increase was found for ferulic or $p$-coumaric acids after extrusion in the present study. Perhaps the free phenolic aicds are very vulnerable in its free form, which could be soon decomposed after it is released from its bound form during extrusion $\left(110-140^{\circ} \mathrm{C}\right)$. In addition, the free phenolic aicds could also permeate into the starch during extrusion leading to the decrease of their contents. Correlation analysis (Table 4) showed no significant relationship between total phenolic acid against antioxidant capacity (for TEAC: $r=0.058, p>0.05$; for DPPH: $r=0.164$, $p>0.05$; for FRAP: $r=0.221$, $p>0.05$ ), because most of the phenolic acids were decomposed after processing. It also indicates that the total phenolic acids are not the major components in free TPC.

Table 4. Correlation analysis of antioxidant capacity and content of antioxidant compounds of raw and extruded grain

\begin{tabular}{|c|c|c|}
\hline & Total phenolic content & Total phenolic acid content ${ }^{\mathrm{a}}$ \\
\hline \multicolumn{3}{|c|}{ Free phenolic extracts } \\
\hline TEAC & $0.815^{* *}$ & $0.164^{\text {n.s. }}$ \\
\hline $\mathrm{DPPH}$ & $0.674^{* *}$ & $0.058^{\text {n.s. }}$ \\
\hline FRAP & $0.823^{* *}$ & $0.221^{\text {n.s. }}$ \\
\hline \multicolumn{3}{|c|}{ Bound phenolic extracts } \\
\hline TEAC & $0.988^{* *}$ & $0.951^{* *}$ \\
\hline $\mathrm{DPPH}$ & $0.978^{* *}$ & $0.912^{* *}$ \\
\hline FRAP & $0.979^{* *}$ & $0.945^{* *}$ \\
\hline \multicolumn{3}{|c|}{ Free + Bound phenolic extracts ${ }^{b}$} \\
\hline TEAC & $0.914^{* *}$ & $0.733^{* *}$ \\
\hline $\mathrm{DPPH}$ & $0.768^{* *}$ & $0.560^{* *}$ \\
\hline
\end{tabular}

${ }^{* *} \mathrm{p}<0.01$

n.s.: not significant

${ }^{\mathrm{a} B}$ Both ferulic acid and $p$-coumaric acid are considered.

${ }^{\mathrm{b}}$ Both free and bound fractions are considered.

In the bound fraction of brown rice, the contents of ferulic and $p$-coumaric acids are $299.0 \pm 1.0$ and $145.8 \pm$ $3.2 \mu \mathrm{g} / \mathrm{g} \mathrm{DW}$, which is respectively over 6 and 4 times higher than the free fraction of the phenolic acid. Similar results from previous studies support that phenolic acid are abundant in their bound form, especially for ferulic acid and $p$-coumaric acids, which are ester-linked to cell wall polysaccharides $[12,15,35]$. Compared with the free phenolic acids, only about $42 \%, 25 \%, 11 \%$, and $44 \%$ of the total phenolic acids were lost after extrusion (110$140^{\circ} \mathrm{C}$ ), respectively. The bound fraction of wheat and maize had a similar trend during processing. Phenolic acids of barley also decreased after extrusion $(-15 \%, \mathrm{p}<$ $0.05)$ at $140^{\circ} \mathrm{C}$. However, extrusion $\left(110-130^{\circ} \mathrm{C}\right)$ significantly increased the phenolic acids content of barley. Thus, bound phenolic acids are less susceptible during processing compared with the free phenolic acids. Correlation analysis (Table 4) showed a significant relationship between total phenolic acid against antioxidant capacity (for TEAC: $r=0.951$, $\mathrm{p}<0.01$; for DPPH: $r=0.912$, $\mathrm{p}<0.01$; for FRAP: $\mathrm{r}=0.945, \mathrm{p}<0.01$ ). The high correlation between antioxidant capacity and total phenolic acid content also revealed the fact that ferulic acid and $p$-coumaric acid are the major components in bound TPC.

As for the whole ferulic acid and $p$-coumaric acid both in free and bound phenolic extracts, correlation analysis (Table 4) was also conducted with antioxidant capacity. Results showed a statistically high positive correlation between them (for TEAC: $\mathrm{r}=0.733$, $\mathrm{p}<0.01$; for DPPH: $\mathrm{r}$ $=0.560, \mathrm{p}<0.01$; for FRAP: $\mathrm{r}=0.773$, $\mathrm{p}<0.01$ ). This result revealed a fact that whole phenolic acid still has a great impact on the antioxidant though most of the phenolic acids were decomposed during extrusion which should be due to the sufficiency and stableness offered by bound phenolic acid.

\section{Conclusion}

In this study, we investigated changes in the TPC, phenolic acid content, degree of starch gelatinization and antioxidant capacity of different whole grains after extrusion $\left(110-140^{\circ} \mathrm{C}\right)$.

The extrusion significantly affected the indexes above. TPC, phenolic acid content, and antioxidant capacity can be retained or even enhanced when an appropriate extrusion temperature is adopted. Extruded $\left(120^{\circ} \mathrm{C}\right)$ wheat and barley suggests that processed whole grains may have more health benefits than the raw material.

In conclusion, the results provide useful information on how the antioxidant components, degree of starch gelatinization and antioxidant capacity changes in different whole grains during extrusion. Thus, the results might be valuable in commercial extrusion for better retention or enhancement of the antioxidants in whole grains.

\section{Acknowledgement}

We gratefully acknowledge Professor Hui Zhang and our colleagues for the excellent guidance and technical assistance during this study. This study is financially 
supported by Project of China National Key Technology Research and Development Program for the 12th Fiveyear Plan (No.2012BAD34B08) and Priority Academic Program Development (PAPD) of Jiangsu Higher Education Institutions.

\section{References}

[1] Slavin, J., "Why whole grains are protective: biological mechanisms,” Proc Nutr Soc, 62 (01). 129-134. 2003.

[2] Zhang, G., Malik, V.S., Pan, A., Kumar, S., Holmes, M.D., Spiegelman, D., Lin, X. and Hu, F.B., "Substituting brown rice for white rice to lower diabetes risk: a focus-group study in Chinese adults,” J Am Diabet Assoc, 110 (8). 1216-1221. 2010.

[3] Anderson, J.W., Hanna, T.J., Peng, X. and Kryscio, R.J., "Whole grain foods and heart disease risk," J Am Coll Nutr, 19 (sup3). 291S-299S. 2000.

[4] Jacobs, D.R., Steffen, L.M., "Nutrients, foods, and dietary patterns as exposures in research: a framework for food synergy," Am $J$ Clin Nutr, 78 (3). 508S-513S. 2003.

[5] Murtaugh, M.A., Jacobs, D.R., Jacob, B., Steffen, L.M. and Marquart, L., "Epidemiological support for the protection of whole grain against diabetes,” Proc Nutr Soc, 62 (01). 143-150. 2003.

[6] Liu, R.H., "Whole grain phytochemicals and health," J Cereal Sci, 46 (3). 207-219. 2007.

[7] Chandrasekara, A., Shahidi, F., “Antiproliferative potential and DNA scission inhibitory activity of phenolics from whole millet grains,” J Funct Foods, 3 (3). 159-170. 2011.

[8] Dillard, C.J., German, J.B., "Phytochemicals: nutraceuticals and human health,” J Sci Food Agric, 80 (12). 1744-1756. 2000.

[9] Miller, H.E., Rigelhof, F., Marquart, L., Prakash, A. and Kanter, M., "Antioxidant content of whole grain breakfast cereals, fruits and vegetables,” J Am Coll Nutr, 19 (sup3). 312S-319S. 2000.

[10] Baublis, A., Decker, E.A. and Clydesdale, F.M., “Antioxidant effect of aqueous extracts from wheat based ready-to-eat breakfast cereals," Food Chem, 68 (1). 1-6. 2000.

[11] Amarowicz, R., Karamac, M., Weidner, S., Abe, S. and Shahidi, F., "Antioxidant activity of wheat caryopses and embryos extracts,” J Food Lipids, 9 (3). 201-210. 2002.

[12] Adom, K.K., Liu, R.H., “Antioxidant activity of grains,” J Agric Food Chem, 50 (21). 6182-6187. 2002.

[13] Adom, K.K., Sorrells, M.E. and Liu, R.H., "Phytochemical profiles and antioxidant activity of wheat varieties," J Agric Food Chem, 51 (26). 7825-7834. 2003.

[14] Serpen, A., Gökmen, V., Pellegrini, N. and Fogliano, V., "Direct measurement of the total antioxidant capacity of cereal products," J Cereal Sci, 48 (3). 816-820. 2008.

[15] Chandrasekara A, Shahidi F, Content of insoluble bound phenolics in millets and their contribution to antioxidant capacity. J Agric Food Chem 58: 6706-6714 (2010).

[16] Yang, Z., Zhai, W., "Identification and antioxidant activity of anthocyanins extracted from the seed and cob of purple corn (Zea mays L.),” Innov Food Sci Emerg Technol, 11 (1). 169-176. 2010.

[17] Laus, M.N., Tozzi, D., Soccio, M., Fratianni, A., Panfili, G. and Pastore, D., "Dissection of antioxidant activity of durum wheat
(Triticum durum Desf.) grains as evaluated by the new LOX/RNO method," J Cereal Sci, 56 (2). 214-222. 2012.

[18] Bryngelsson, S., Dimberg, L.H. and Kamal-Eldin, A., "Effects of commercial processing on levels of antioxidants in oats (Avena sativa L.),” J Agric Food Chem, 50 (7). 1890-1896. 2002.

[19] Zieliński, H., Michalska, A., Piskuła, M.K. and Kozłowska, H., "Antioxidants in thermally treated buckwheat groats," Molec Nutr Food Res, 50 (9). 824-832. 2006.

[20] Sosulski, F., Krygier, K. and Hogge, L., "Free, esterified, and insoluble-bound phenolic acids. 3. Composition of phenolic acids in cereal and potato flours," J Agric Food Chem, 30 (2). 337-340. 1982.

[21] Singleton, V.L. and Rossi, J.A., "Colorimetry of total phenolics with phosphomolybdic-phosphotungstic acid reagents," Am J Enol Viticult, 16 (3). 144-158. 1965.

[22] Bhattacharya, M. and Hanna, M.A., "Kinetics of starch gelatinization during extrusion cooking," J Food Sci, 52 (3). 764766, 1987.

[23] Brand-Williams, W., Cuvelier, M.E. and Berset, C.L.W.T., "Use of a free radical method to evaluate antioxidant activity," Food Sci Technol-LEB, 28 (1). 25-30. 1995.

[24] Re, R., Pellegrini, N., Proteggente, A., Pannala, A., Yang, M. and Rice-Evans, C., "Antioxidant activity applying an improved ABTS radical cation decolorization assay,” Free Radical Bio Med, 26 (9). 1231-1237. 1999.

[25] Benzie, I.F. and Strain, J.J., "The ferric reducing ability of plasma (FRAP) as a measure of "antioxidant power": the FRAP assay," Anal Biochem, 239 (1). 70-76. 1996.

[26] Chandrasekara, A., Naczk, M. and Shahidi, F., "Effect of processing on the antioxidant activity of millet grains," Food Chem, 133 (1). 1-9. 2012.

[27] Dewanto, V., Wu, X. and Liu, R.H., "Processed sweet corn has higher antioxidant activity,” J Agric Food Chem, 50 (17). 49594964. 2002

[28] Slavin, J.L., Jacobs, D. and Marquart, L., "Grain processing and nutrition,” Crit Rev Food Sci, 40 (1). 309-326. 2000.

[29] Davis, D.A. and Arnold, C.R., "Effects of two extrusion processing conditions on the digestibility of four cereal grains for Penaeus vannamei,” Aquaculture, 133 (3). 287-294. 1995.

[30] Nicoli, M.C., Anese, M., Parpinel, M.T., Franceschi, S. and Lerici, C.R., "Loss and/or formation of antioxidants during food processing and storage,” Cancer Lett, 114 (1). 71-74. 1997.

[31] Pedrielli, P., Pedulli, G.F. and Skibsted, L.H., “Antioxidant mechanism of flavonoids. Solvent effect on rate constant for chain-breaking reaction of quercetin and epicatechin in autoxidation of methyl linoleate," J Agric Food Chem, 49 (6). 3034-3040. 2001.

[32] Pérez-Jiménez, J. and Saura-Calixto, F., "Effect of solvent and certain food constituents on different antioxidant capacity assays," Food Res Int, 39 (7). 791-800. 2006.

[33] Pan, G.X., Bolton, J.L. and Leary, G.J., "Determination of ferulic and p-coumaric acids in wheat straw and the amounts released by mild acid and alkaline peroxide treatment," J Agric Food Chem, 46 (12). 5283-5288. 1998.

[34] Bartolome, B. and Gómez-Cordovés, C., "Barley spent grain: release of hydroxycinnamic acids (ferulic and p-coumaric acids) by commercial enzyme preparations," J Sci Food Agric, 79 (3). 435-439. 1999.

[35] Ishii, T., "Structure and functions of feruloylated polysaccharides," Plant Sci, 127 (2). 111-127. 1997. 